\title{
Healthcare Payments Under the Budget Deal: Mostly Good News for Physicians
}

In the early morning hours last Friday (2/9/18) Congress passed and President Trump signed a massive budget agreement (1). The spending package will cost about $\$ 320$ billion over 10 years, according to the Congressional Budget Office. Payments for healthcare substantially increase under the deal. Most praised the agreement.

"Congress made the right choice this morning for patients and communities by voting to halt damaging cuts to hospitals that care for low-income working families and others who face financial challenges," said Dr. Bruce Siegel, CEO of America's Essential Hospitals, which represents the nation's safety-net facilities. Marc Goldwein of the Center for a Responsible Federal Budget called the healthcare provisions the one "beacon of light" in what otherwise is an exorbitantly costly budget bill. Goldwein praised its mix of structural reforms with "reasonable policy" and liked that the bill pays for the increased healthcare spending.

The bill extends Medicare physician fee cuts that provide about $\$ 38$ billion in offsets to the increased spending (2). The bill preserves the planned physician fee cuts at $0.5 \%$ in 2018 but would reduce the cut to $0.25 \%$ in 2019 . Not all were pleased by the continuation of the cuts. Calling it "contrary to Congress' intent" ACP President Jack Ende called on Congress to enact permanent relief from the physician fee cuts.

Other major healthcare provisions include $(1,2)$ :

- Continued funding for community health centers for two years.

- A two-year delay to the already-in-effect payment cuts to Medicaid disproportionate-share hospitals (DSH) which predominately represent safety net hospitals.

- A two-year delay in the low-volume adjustment program which predominately affects rural hospitals.

- An additional 4-year extension of the Children's Health Insurance Program (CHIP), which had received a 6-year extension in the continuing resolution that was approved in January.

- Forcing pharmaceutical companies to pay 75 percent of the cost of drugs for seniors in Medicare's coverage gap a year earlier than planned.

- Repeal of the "therapy cap", a move long pushed by therapy provider groups and the American Association of Retired Persons. This would permanently repeal Medicare's coverage limit on physical therapy, speech-language pathology, and outpatient treatment.

- \$6 billion for the opioid epidemic, which will go toward state grants, public prevention programs, and law enforcement.

- Funding for the Maternal, Infant, and Early Childhood Home Visiting Program, which helps at-risk pregnant women and families navigate the social safety net.

- A reduction in Medicare payments to Home health agencies. They're expected to lose $\$ 3.5$ billion in Medicare payments starting in 2020 due to a change in the way Medicare calculates annual payment updates. 
- Funding the Chronic Care Act, which opens up new flexibilities for Medicare Advantage and care for chronically ill Medicare beneficiaries.

- A 2-year delay in implementing The Affordable Care Act's high-cost plan tax, popularly known as the "Cadillac tax". This was a 40 percent excise tax on employer plans exceeding $\$ 10,200$ in premiums per year for individuals and $\$ 27,500$ for families. The tax is now scheduled to take effect in 2020 .

- Repeal of Independent Payment Advisory Board (IPAB). Provider groups from the American Medical Association to the American Hospital Association applauded the move, even though Congress has never triggered the panel, which was charged to find and implement Medicare savings.

However, not all were pleased by the repeal of cost containments. IPAB repeal doesn't cost much in the grand scheme of things, said Mark Goldwein from the Center for a Responsible Federal Budget but "the long-term policy implications are huge, and a big mistake" (2). Kaiser Family Foundation Senior Vice President Larry Levitt chided that the bill demonstrates "...healthcare cost containment generally seems better in theory than in practice" (2).

Richard A. Robbins, MD

Editor, SWJPCC

\section{References}

1. Luthi S. Beacon of light: Healthcare additions in budget law pleasantly surprise providers. Modern Healthcare. February 9, 2018. Available at:

http://www.modernhealthcare.com/article/20180209/NEWS/180209895 (accessed 2/12/18).

2. Ault A. Trump signs budget deal, cuts Medicare fee in 2019. Medscape. February 9, 2018. Available at: https://www.medscape.com/viewarticle/892491 (accessed 2/12/18). 